\title{
The effect of PCM layer on the natural air flow movement in the façade cavity of BiPV system
}

\author{
Jakub Čurpek ${ }^{1,2^{*}}$, and Miroslav Čekon ${ }^{2,1}$ \\ ${ }^{1}$ Slovak University of Technology, Faculty of Civil Engineering, Bratislava, Slovakia \\ ${ }^{2}$ Brno University of Technology, Faculty of Civil Engineering, Brno, Czechia
}

\begin{abstract}
The incorporation of a phase change material (PCM) in building integrated photovoltaic (BiPV) façade can be applied to improve its thermal performance including more effective electrical conversion, however their real interaction needs to be investigated at adequate level. The aim of the presented paper is focused on the application of a material with high latent heat capacity based on PCM in the structure of double-skin BiPV façade. The key aspect concerns on an analysis of natural air flow movement affected by the storing/releasing heat energy from the PCM during daytime/night-time of days. The experimental campaign was performed using an experimental outdoor test cell where two full-scale façade samples (reference BiPV and experimental BiPV/PCM) were investigated. The strong effect of thermal inertia of the PCM identified by experimental measurements was observed on the façade air cavity temperature and air flow movement. Experimental results revealed that natural air flow regimes in façade cavities are nearly equal in the daytime, but in the night-time are totally different. The thermal emission from PCM increase the air temperature in the façade cavity and increase the velocity of air flow movement (PCM started solidified), mainly in the night-time.
\end{abstract}

\section{Introduction}

Many research studies have been focused on different ways for an optimization of building energy performance according to the world energy policy. Building envelope system presents crucial part within the campaign of energy demand reduction. Integration of renewable sources into façade systems together with a combination of advanced responsive materials reveal essential possibly for overcome the actual world energy situation. Accordingly, the presented study is aimed on the novel type of the advanced double-skin façade with an outer layer of building integrated photovoltaic (BiPV) system coupled with a phase change material (PCM). The façade system is structured with the intermediate air cavity in the ventilated and non-ventilated regime. The key function of the façade is based on the reduction of peak operating temperatures of the photovoltaic (PV) modules by PCM and to affect thermal response of air temperature inside the façade cavity. Huang et al. [1,2] performed comprehensive research focused on PCMs for thermal management of limiting temperature rise in BiPV systems at concept stage.

PCM stores a high amount of energy by latent heat of fusion during its phase change (in this case - from solid to liquid) and increases thermal inertia of the façade. This phenomenon directly influences thermal regimes in the façade cavity (velocities of the air flow movement and air temperatures) in different ways during daytime/night-time of days. Thermal performance of
PCM outer layer in the ventilated façade was experimentally and numerically investigated by Diarce et al. $[3,4]$, by using the outdoor test cell facility (city of Vitoria-Gasteiz in Spain) and the 2D simulation model by CFD method. The dimension of the façade air cavity was $60 \mathrm{~mm}$ with the forced air flow movement. The experimental results demonstrated that the air flow movement through the façade cavity was overheated up to $12{ }^{\circ} \mathrm{C}$ during the daytime of a day. The cavity air temperature was warmer by $2{ }^{\circ} \mathrm{C}$ than outside air temperature 2.5 hours after the sunset time (effect of PCM solidification). De Gracia et al. [5] experimentally investigated thermal performance of a ventilated double skin façade with PCM in its air cavity by two identical house-like cubicles located in Puigverd de Lleida, Spain. Three different regimes of air flow movement in the façade were performed: free floating, controlled temperature and demand profile conditions. In case of free floating, the ventilated facade with PCM increased indoor temperature from $9{ }^{\circ} \mathrm{C}$ to $18{ }^{\circ} \mathrm{C}$ in comparison with reference cubicle in the winter.

Lamnatou et al. [6] generally overviewed possibilities of multiple energy storage solutions in BiPV and BiPV/T (thermal) systems. Especially, Ma et al. [7] presented actual comprehensive literature review of PV/PCM system, with the focus on technology overview, material selection and determination strategy of phase transition temperature. Experimental investigation of PV/T-PCM was performed in numerous

\footnotetext{
* Corresponding author: jakub.curpek@stuba.sk
} 
research studies [8,9] with different system configurations.

Xiang [10] numerically analysed, and experimentally investigated the PV/PCM air system (laboratory conditions). The air flow velocity in the cavity increased sharply during the first 60 minutes as the temperature increased, after which it remained stable at $0.14 \mathrm{~m} / \mathrm{s}$ due to the PCM melting process. After the PCM fully melted, the air flow velocity increased sharply to 0.27 $\mathrm{m} / \mathrm{s}$, reaching its maximum temperature over the test period. During the solidification process of the PCM, the airflow rate maintained about $20 \mathrm{~L} / \mathrm{s}$ for 700 minutes, after which it decreased gradually to $15 \mathrm{~L} / \mathrm{s}$. It was concluded that the emitted heat from PCM can enhance night ventilation and decrease the building energy consumption.

Elarga et al. [11] developed physical-mathematical model for double-skin façade with PV/PCM layer and carried out numerical simulations to evaluate the integration of PCM layer into a ventilated transparent façade. The study shows that the integration of a PCM layer in the façade cavity, in combination with a semitransparent PV layer, leads to a reduction in the monthly cooling energy demand in the range $20-30 \%$.

Kant el al. [12] performed the comprehensive numerical study of the effects of different BiPV design parameters namely, BiPV height air gap between BiPV/PCM and wall, PCM thickness, and air mass flow rate on the maximum PV panel temperature, the power production by the PV, and the energy extracted by the air.

The integration of PCM into the double-skin BiPV façade was the main structural concept in this research study. The influence of PCMs on the real performance of the BiPV façade and effectivity of application of latent thermal energy storage used on reduction of the peak operating temperatures of the PV modules as well as shifting of air temperature inside the façade cavity is analysed at full-scale level by authors in $[13,14]$. Accordingly, the special attention is here focused on the natural air flow movement in the façade cavity in dependency on the PCM thermal effect at real climate conditions. In the following parts, research methodology, experimental methods and findings are presented.

\section{Methodology and façade samples}

The aim of the research was the investigation of the direct impact of melting and solidification process in PCM on natural air mass flow rate in the façade cavity. Therefore, two types of double-skin BiPV façade were experimentally examined with PCM layer at the rear side of PV modules (BiPV/PCM tested sample) and without PCM (BiPV reference sample), in both ventilated and non-ventilated regime. The key part of the measurements was focused on the velocity of the air flow and temperature distribution through the façade fragments. The fundament structure of the investigation process is based on:

- experimental measurements of two façade types in real outdoor conditions by an outdoor test cell,
- comparative analysis of the façade types in terms of the thermal effect of the PCM in daytime/night-time of a day,

- comparative analysis of two façade cavity regimes in terms of the natural ventilation rates (ventilated and non-ventilated regime),

- analysis of the dependency between incident solar radiation on the façade and air temperature in the façade cavity.

There are fundamental assumptions that determinate the PCM integration based mainly for increasing the cavity air temperature in night-time of a day (emission of latent thermal energy), and in daytime of a day (accumulation of latent thermal energy) (Fig. 1). Moreover, the velocity of air flow movement will be significantly influenced during the phase change process of PCM as well as the utilization of its latent heat capacity.

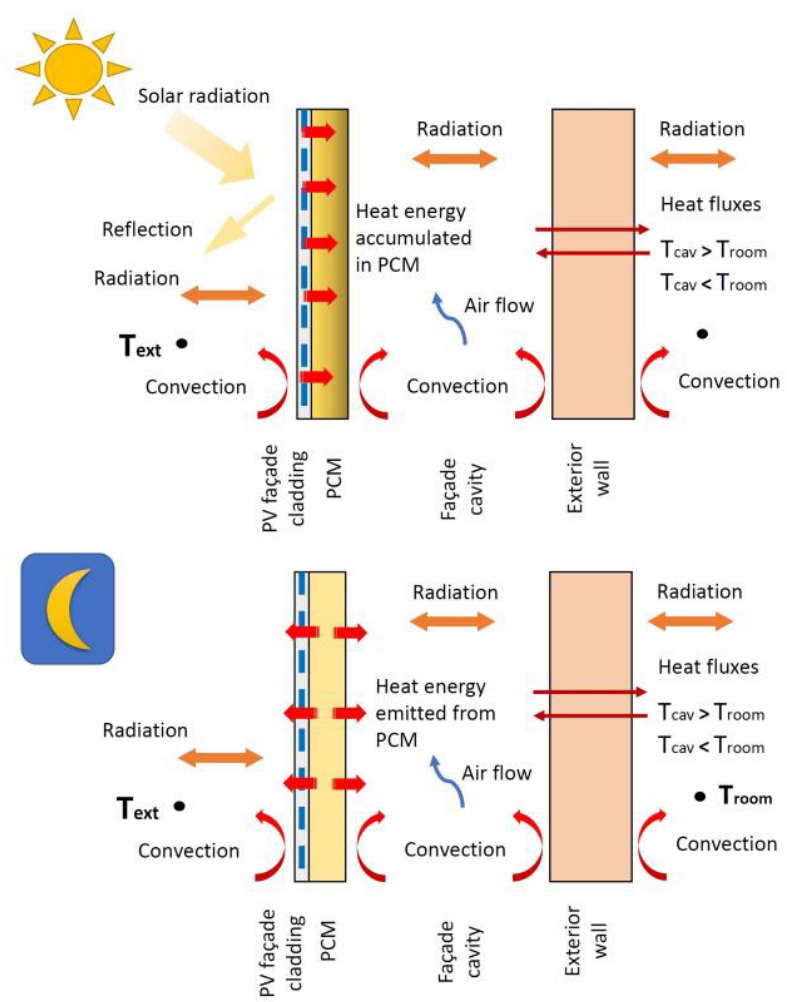

Fig. 1. BiPV façade schemes with PCM in two periods of a day

\section{Experimental campaign}

The experimental measurements of the façade samples (BiPV, BiPV/PCM) were performed by an experimental outdoor test cell created and located at the AdMaS research centre operated by Brno University of Technology (longitude $16^{\circ} 34^{\prime}$, latitude $49^{\circ} 14^{\prime}$, altitude $297.23 \mathrm{~m})$. The test cell with outer dimensions $3.0 \mathrm{~m} \times$ $2.43 \mathrm{~m} \times 3.09 \mathrm{~m}$ has been specially developed for testing and investigation façade elements (Fig.2). The outside three walls of the test cell were separately mounted as lightweight structure filled with $150 \mathrm{~mm}$ mineral wool (with vapor and vapor-open membranes on interior and exterior side respectively) enclosed by gypsum board at inside and ventilated wood cladding at outside. The 
remaining south oriented wall was mounted also as lightweight structure filled with $100 \mathrm{~mm}$ mineral wool enclosed by gypsum board at inside and wooden supporting elements for PV cladding at outside. The thermally insulated (50 mm polystyrene) spaces $(1.2 \mathrm{~m} \times$ $1.0 \mathrm{~m} \times 2.3 \mathrm{~m}$ ) were mounted behind each façade sample and is separated from each internal construction for ensure quasi-adiabatic conditions (Fig. 3), due to prevent the influence of other heat transfer processes. The compensation space of the cell was thermally controlled by one local heating/cooling unit (adjusted value $23{ }^{\circ} \mathrm{C}$ ). BiPV façade system was mounted as a façade cladding system - Ruukki Liberta Solar panels based on CIGS (copper-indium-gallium-selenide) film technology, with the glass module dimensions $1190 \mathrm{~mm} \times 790 \mathrm{~mm}$. The aluminium containers filled with paraffin based PCM RT 27 (from Rubitherm $\mathrm{GmbH}$, Germany) were mounted on the rear side of the PV panels within BiPV/PCM façade test element. The melting temperature and heat storage capacity of the PCM are in the range of $25-28{ }^{\circ} \mathrm{C}$ and $180 \mathrm{~kJ} / \mathrm{kg}$, respectively.

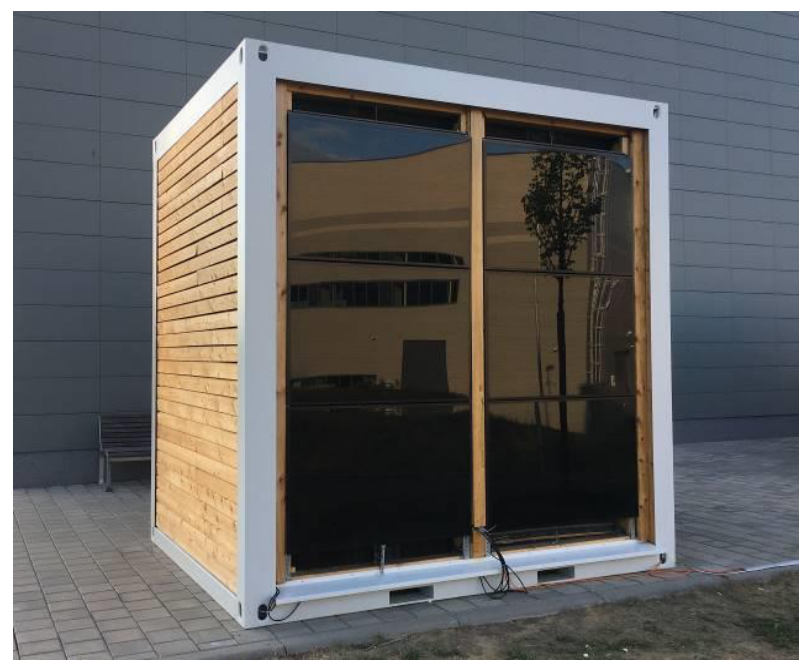

Fig. 2. The experimental outdoor test cell

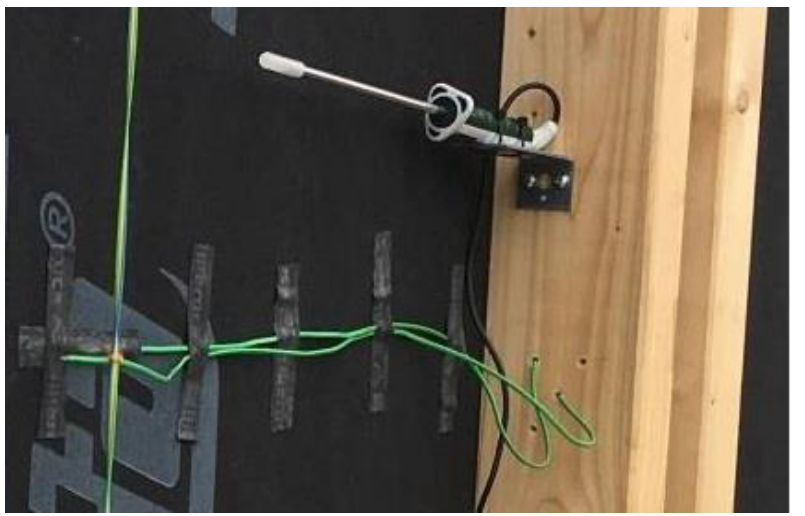

Fig. 4. Thermoanemometer with the thermocouple in the middle position of the façade cavity

The investigated façade systems are divided into three levels within the height according to dimensions of the one PV panel $(1.19 \mathrm{~m} \times 0.79 \mathrm{~m})$. At each level of the façade, the one group of sensors are mounted through the façade fragment, except of sensor for measuring velocity of air flow in the façade cavity (only middle positions) and heat flux sensors at the interior side (Fig. 4). The temperature sensors were used Ahlborn Alemeno thermocouples type $\mathrm{K}$, and resistor-based sensors (Pt 100). Digital thermoanemometer Ahlborn Almeno FVAD35TH4 was used to measure the velocity of air flow movement (Fig. 4). The climate conditions were measured by a local weather data station (solar radiation, outside air temperature, wind speed and direction).
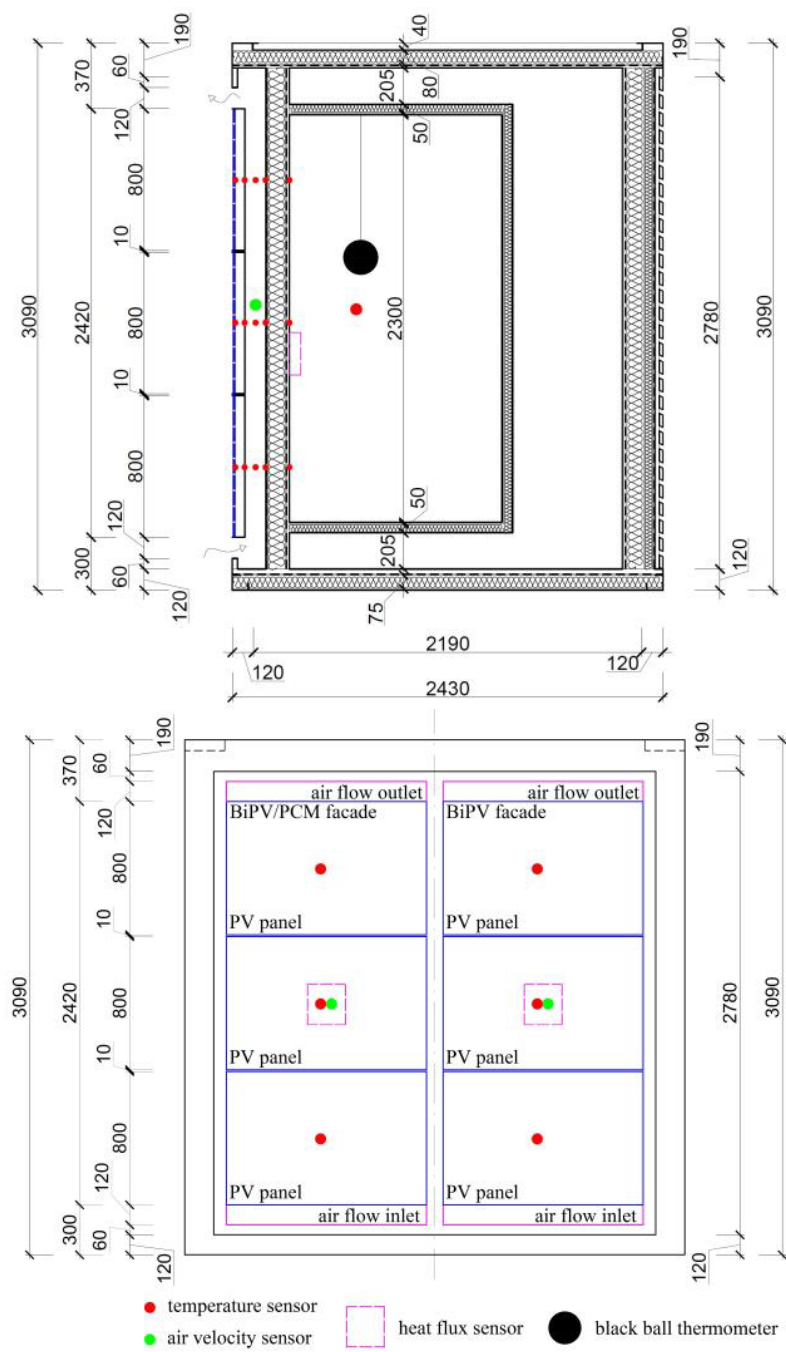

Fig. 3. Cross-section of the test cell (up) and fort view of the façade with arrangement of sensors through height of the façades (bottom).

\section{Experimental results}

Two test scenarios were measured by varying of activation natural ventilation regime in the façade cavity of two different experimental façade models (BiPV and $\mathrm{BiPV} / \mathrm{PCM}$ ). Both models were tested in two natural ventilation modes. The first test scenario represents a non-ventilated case, which means both openings (bottom and top) of the façade cavity were fully closed, while the second demonstrates a ventilated case with the inlet and outlet openings both fully opened. Accordingly, the investigated non-ventilated and ventilated test case has been tested respectively. These two test cases were conducted during the late summer season in several days respectively, however two sunny days are analysed with similar climate conditions. The experimental results 
were taken under outdoor conditions where the maximum sun height above the horizon (around $45^{\circ}$ and $41^{\circ}$ respectively) was at midday. This corresponds to a $45^{\circ}$ and $41^{\circ}$ incline from the normal angle of incidence representing the maximum global horizontal radiation of $660 \mathrm{~W} / \mathrm{m}^{2}$ and $610 \mathrm{~W} / \mathrm{m}^{2}$ at the tested location. At the same time, the highest outdoor ambient temperatures were reached at the level of a maximum $26.4{ }^{\circ} \mathrm{C}$. The wind velocity $\left(v_{\mathrm{w}}\right)$ varied in the range from 0.24 to 1.51 $\mathrm{m} / \mathrm{s}$ (non-ventilated) and 0.25 to $2.73 \mathrm{~m} / \mathrm{s}$ (ventilated).

The testing period was thus specified for the thermal performance analysis of the climate response regarding the overheating aspect in the façade cavity and the maximum solar heat gain achieved. Overall, the outdoor ambient temperature $\left(T_{\mathrm{ae}}\right)$ varied from a night-time $+11.8^{\circ} \mathrm{C}$ up to a daytime $+26.4^{\circ} \mathrm{C}$. The incident horizontal solar radiation rate $\left(I_{\mathrm{gh}}\right)$ reached a maximum at midday in the area where samples were measured during totally clear sky conditions. The data presented in the graph (Fig. 5) shows the results of the climate parameters for both non-ventilated and ventilated test regimes respectively. Time-step of data acquisition was set for one minute.
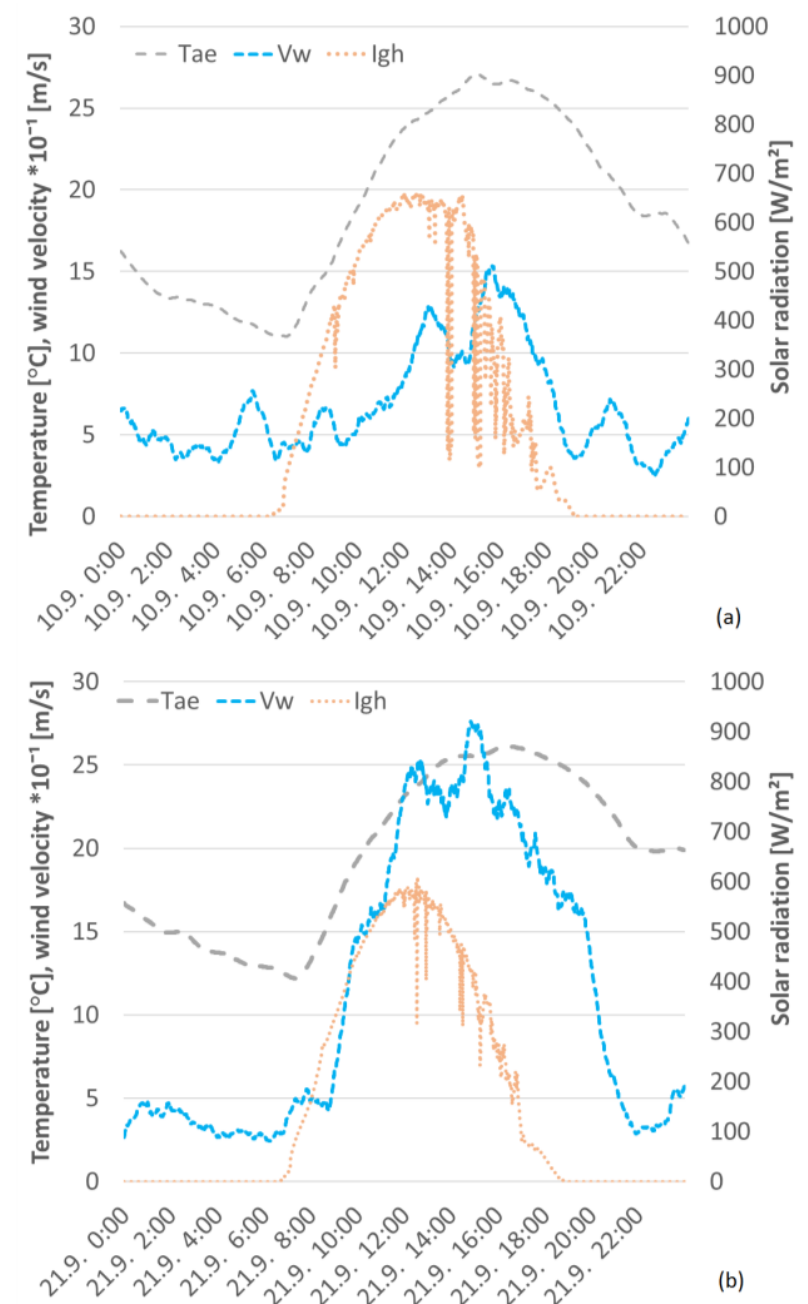

Fig. 5. Climate conditions during late summer season; (a) first and (b) second test day.

The experimental results revealed that the differences in the air flow velocity $\left(v_{\mathrm{ac}}\right)$ measured at two periods of day (daytime and night-time) are significant. The change of ventilation regime in the façade cavity from ventilated to non-ventilated considerably influenced the thermal performance of the façade cavity.

In case of non-ventilated regime, certain air flow movement occurred in the cavity. BiPV system had a higher $v_{\mathrm{ac}}$ in the daytime ( $\max . v_{\mathrm{ac}}=0.26 \mathrm{~m} / \mathrm{s}$ at midday), due to the absence of heat accumulation layer. In this period, BiPV/PCM works as a thermal buffer (melting process) and significantly delays the inception of heat impact by solar radiation. The max. difference of velocity of air flow movement $\left(\Delta v_{\mathrm{ac}}\right)$ is $0.1 \mathrm{~m} / \mathrm{s}$ at midday. However, in the night-time occurred the reverse effect and air flow movements are totally different due to emission of thermal energy from PCM (solidification process), which increases the air temperature in the façade cavity by thermal emittance. This physical phenomenon increases the velocity of air flow movement due to increasing thermal field in the façade cavity (Fig. 6a). The max. $\Delta v_{\text {ac }}$ in the façade cavity in case of BiPV and BiPV/PCM façade is $0.1 \mathrm{~m} / \mathrm{s}$ during the night-time. Additionally, it should be considered, that the differences in the night-time are occurred in longer time than during the daytime, where time of continuous PCM melting process is conditioned by value of $T_{\mathrm{ae}}$.
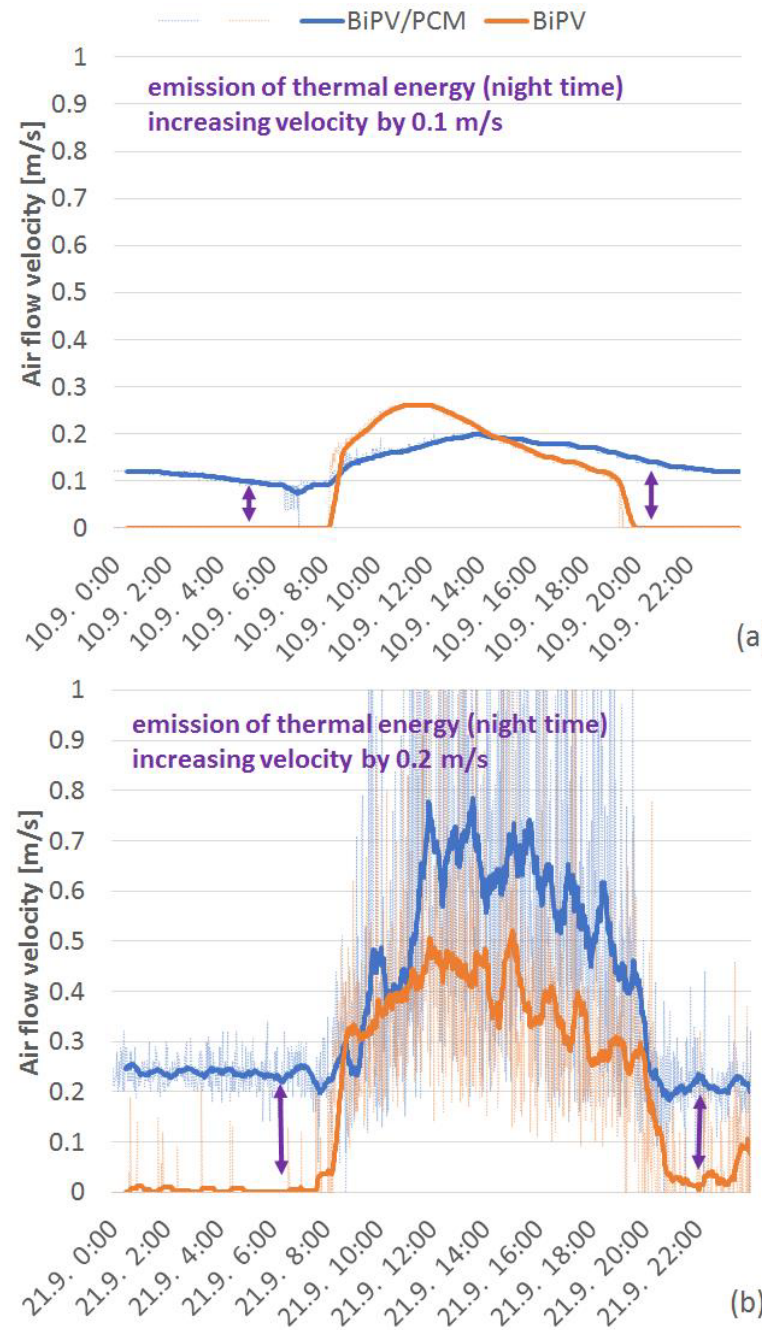

Fig. 6. Air velocity vac for in the façade cavity of a BiPV and $\mathrm{BiPV} / \mathrm{PCM}$; (a) non-ventilated and (b) ventilated test case. 
On the other hand, the façade cavities have a more complex performance in the case of ventilated regime, where high latent heat capacity of the PCM can be fully utilized in sunny/night period (Fig. 6b). Accordingly, BiPV/PCM system had a higher $v_{a c}$ at midday (max. average $v_{\mathrm{ac}}=0.79 \mathrm{~m} / \mathrm{s}$ at midday) mainly due to higher value of wind speed $\left(v_{\mathrm{w}}=2.73 \mathrm{~m} / \mathrm{s}\right)$. However, in nighttime of the investigated day, the air flow velocities are totally different due to emission of thermal energy from PCM and have a continuous function (from evening to morning). The max. average value of $\Delta v_{\mathrm{ac}}$ in the façade cavity in case of BiPV and BiPV/PCM façade is $0.2 \mathrm{~m} / \mathrm{s}$ during the night-time. Moreover, the strong effect of thermal inertia of PCM also influences the air temperature in the façade cavity $\left(T_{\mathrm{a}, \mathrm{cav}}\right)$. According to experimental measurements, the max. differences of $T_{\mathrm{a}, \mathrm{cav}}$ are in two parts of day. In non-ventilated case, the PCM can decrease the peak value $T_{\mathrm{a} \text {,cav }}$ by $26 \mathrm{~K}$ at midday and subsequently during the night-time increase the temperature by $4 \mathrm{~K}$ (Fig. 7a).
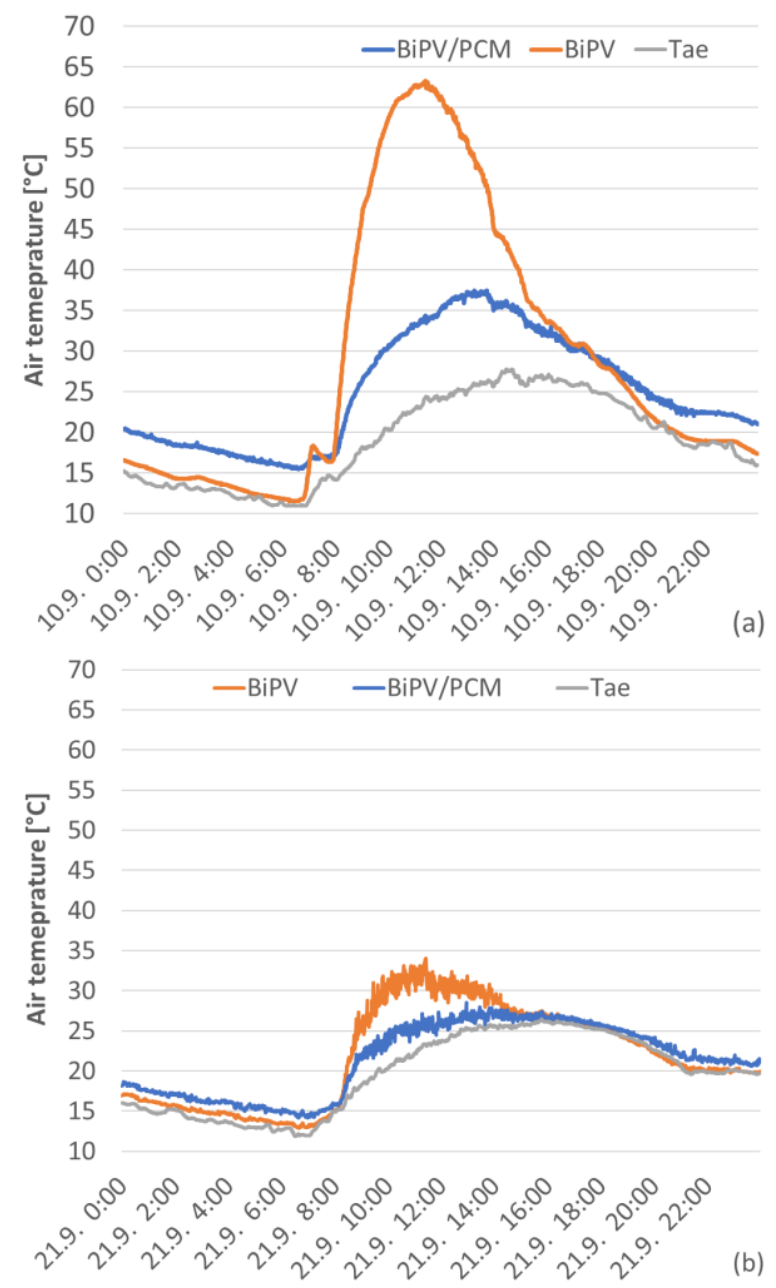

Fig. 7. BiPV and BiPV/PCM air temperature in the facade cavity (middle position) $T_{\mathrm{a} \text {,cav }}\left[{ }^{\circ} \mathrm{C}\right]$ and external air ambient temperature $T_{\mathrm{ae}}$; (a) non-ventilated and (b) ventilated test case.

However, in case of the ventilated regime, the max. differences of $T_{\mathrm{a} \text {,cav }}$ are also in two parts of day. At midday the value $T_{\mathrm{a} \text {,cav }}$ in case of the BiPV/PCM sample is decreased by $6 \mathrm{~K}$ at midday and subsequently during the night-time of day is increased by $1 \mathrm{~K}$ in comparison with BiPV test sample (Fig. 7b).

The dependencies between incident vertical solar radiation $I_{\mathrm{gv}}$ on the façade sample and the air temperature in the façade cavity determinates that the PCM layer plays a key role in overall thermal inertia of the façade system. At the peak level up to $I_{\mathrm{gv}}=780 \mathrm{~W} / \mathrm{m}^{2}, \mathrm{PCM}$ can decrease the values of $T_{\mathrm{a}, \mathrm{cav}}$ by $30 \mathrm{~K}$ in nonventilated case (Fig. 8a) at one time without the consideration of peak values - thermal delay effect. Moreover, the effective usage of the PCM latent heat capacity is determined by the points in the diagram around the level of PCM phase change temperature $T_{\text {pcm }}=27{ }^{\circ} \mathrm{C}$. Additionally, the effect of PCM is lower in ventilated case, where the max. $\Delta T_{\mathrm{a} \text {,cav }}$ is $6 \mathrm{~K}$ as a result of the effect of natural air flow movement in the cavity, which significantly cooled down the rear side of façade samples (Fig. 8b). The latent heat capacity of the PCM was not fully utilized in the daytime and the time of solidification is longer in comparison with the nonventilated regime.

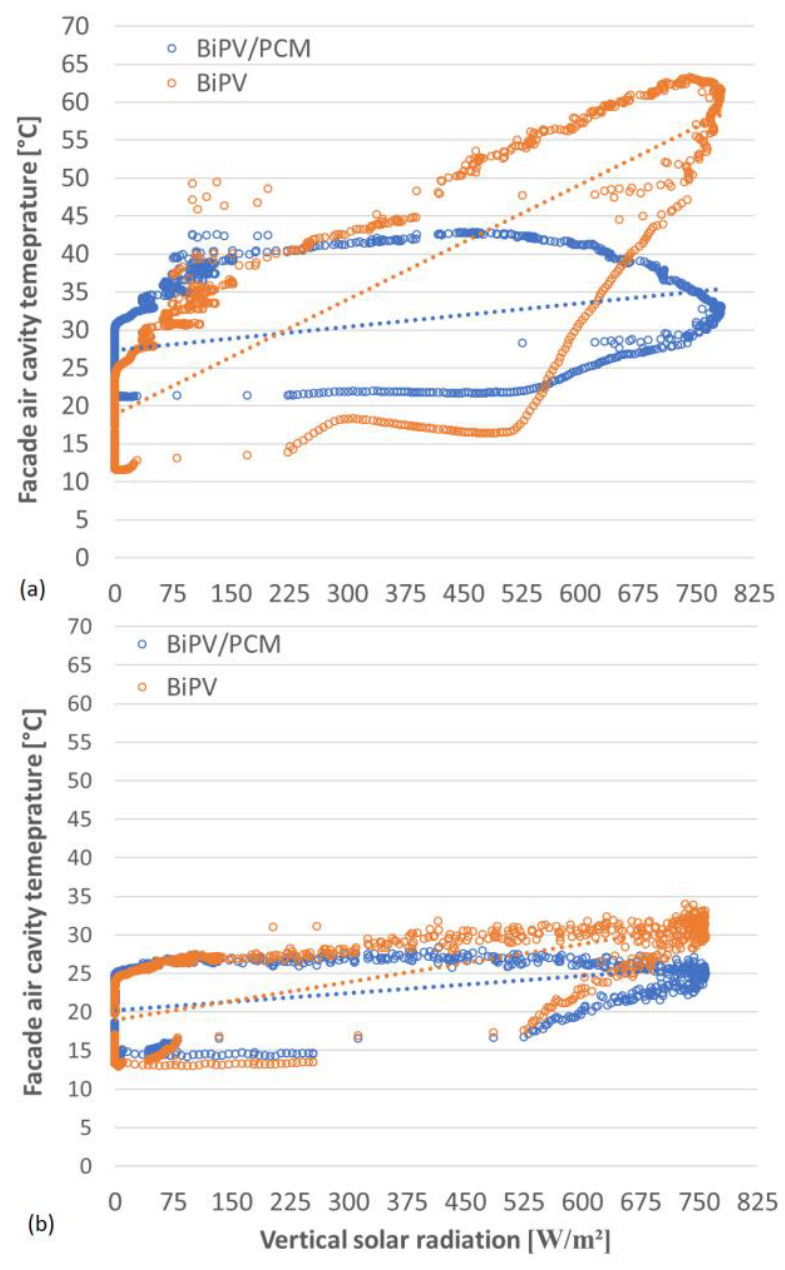

Fig. 8. BiPV and BiPV/PCM, the effect of the vertical solar radiation that responds on the air temperature in facade cavity; (a) non-ventilated and (b) ventilated test case.

The strong effect of the vertical solar radiation was observed on the differences of air temperature in facade cavity between BiPV and BiPV/PCM in both ventilated and non-ventilated case (Fig. 9). The larger part of energy from solar radiation was continuously absorbed 
in the PCM in daytime. The air temperature through the non-ventilated façade cavity increased up to nearly $25 \mathrm{~K}$ in comparison with ventilated case under the peak level of $I_{g v}=780 \mathrm{~W} / \mathrm{m}^{2}$. However, the latent heat emittance from the PCM during the night-time at zero value of $I_{g v}$ caused the increase of $\Delta T_{\mathrm{a} \text {,cav }}$ by $10 \mathrm{~K}$ in non-ventilated case. The values of $\Delta T_{\mathrm{a} \text {,cav }}$ are higher (in the range of $5-$ $15 \mathrm{~K}$ ) in the morning part of the day in comparison with the afternoon part in case of non-ventilated regime. These distinctions are caused by the high thermal inertia of the PCM and its full solidification in the night before. On the other side, in the afternoon part of the day, the PCM latent heat capacity is almost overused (fully melted) and cannot be able to delay the heat impact of solar radiation as in the previous part of the day.

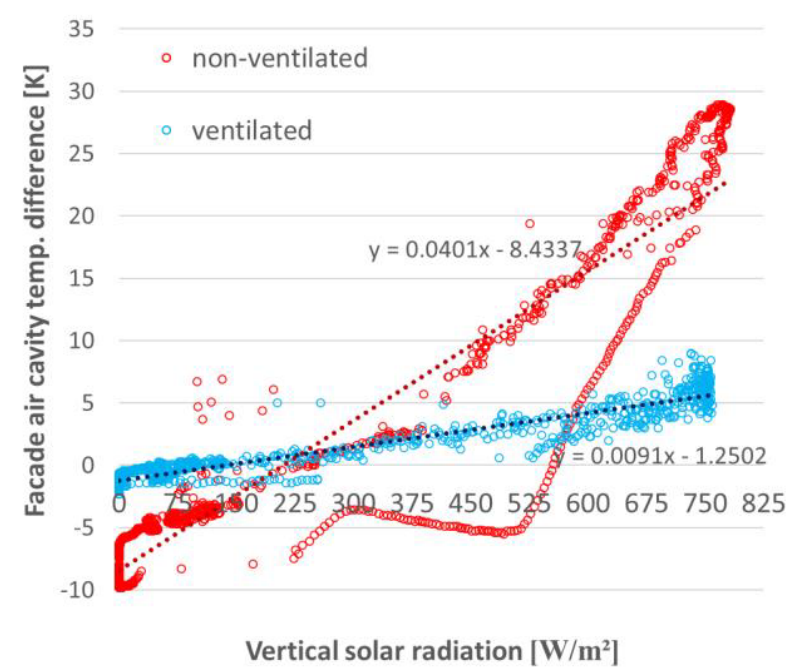

Fig. 9. The effect of the vertical solar radiation that responds on the difference of air temperature in facade cavity between $\mathrm{BiPV}$ and BiPV/PCM.

Additionally, the effect of the vertical solar radiation has a direct impact on the values of $v_{a, c a v}$ in the façade cavity. The dependencies between $I_{g v}$ on the façade sample and the $v_{a, c a v}$ in façade cavity are significant. The emission and accumulation of latent heat energy in PCM directly influences the air flow movement in the cavity. The surface temperature of PCM container on the rear side is higher in comparison with simple BiPV structure during the night-time due to solidification of PCM and continuous emittance of latent heat energy. However, during the daytime, the above-mentioned effect is inverse, the surface temperature of BiPV structure is greatly higher than the surface of PCM container due to melting process of PCM conditioned by heat accumulation.

Accordingly, the effects of convection and radiation heat transfers increase buoyancy driven air flow in the cavity. At the peak level of $I_{g v}=780 \mathrm{~W} / \mathrm{m}^{2}$, PCM can decrease the values of $v_{a, c a v}$ by $0.1 \mathrm{~m} / \mathrm{s}$ in non-ventilated case (Fig. 10a). Additionally, the reverse effect occurred in ventilated case, where the max. difference of $v_{a, \text { cav }}$ is $0.12 \mathrm{~m} / \mathrm{s}$ due to the overuse PCM latent heat capacity in the day before (Fig. 10b).

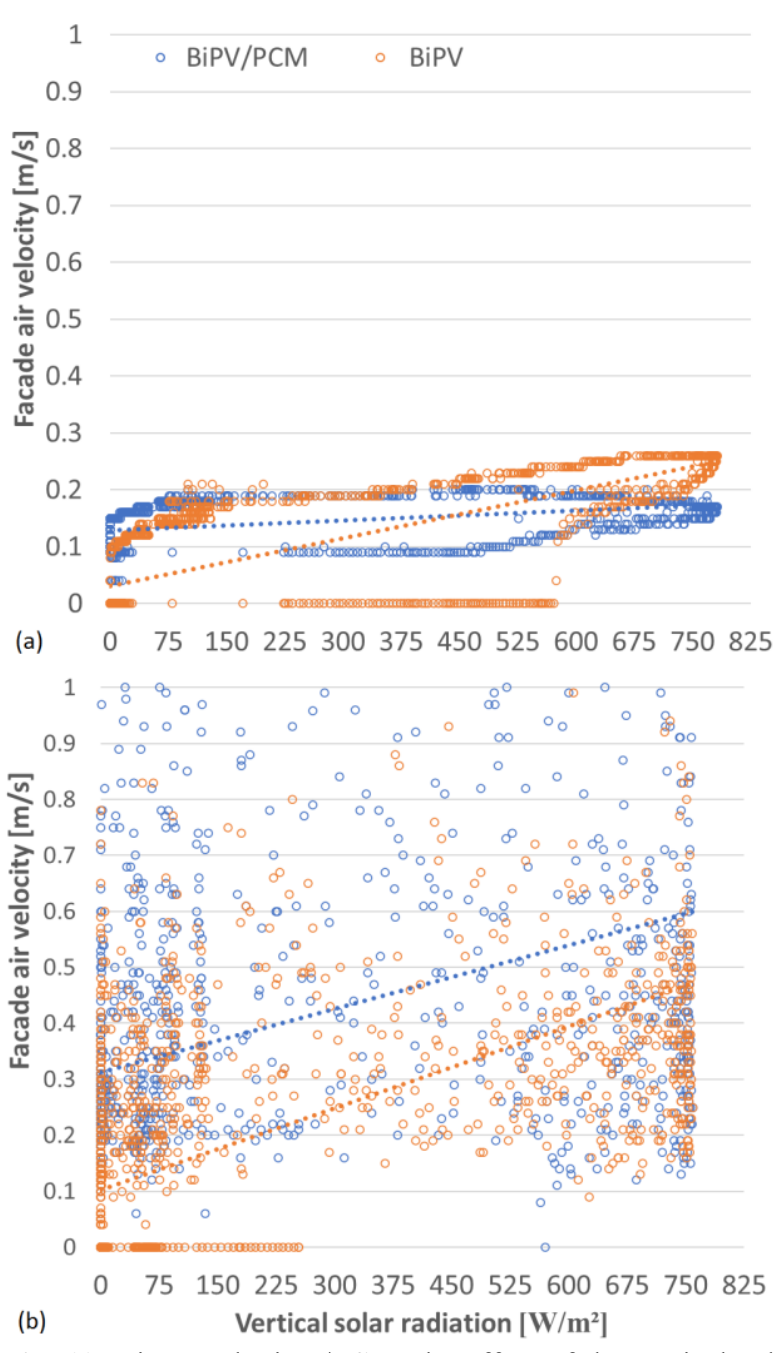

Fig. 10. BiPV and BiPV/PCM, the effect of the vertical solar radiation that responds on the air velocity in facade cavity (a) non-ventilated and (b) ventilated test case.

Surface temperatures in the façade cavity can be decreased by approximately $20 \mathrm{~K}$ in the daytime by application of PCM structure in the non-ventilated BiPV façade system (Fig. 11). This system directly influences convection heat transfer inside the cavity and air flow movement. However, in the night-time, the large amount of stored latent heat inside the PCM continuously emits and its time of heat emission is in dependency with outside air temperature. Thermal regime in the cavity of the $\mathrm{BiPV} / \mathrm{PCM}$ façade is higher (approximately $8 \mathrm{~K}$ ) in comparison with the BiPV sample in the night-time (Fig. 12). However, the ventilated regime of the investigated façade sample can decrease overall overheating inside the cavity, $\Delta T_{\mathrm{a} \text {,cav }}=30 \mathrm{~K}$ (BiPV) and $\Delta T_{\mathrm{a}, \mathrm{cav}}=17 \mathrm{~K}(\mathrm{BiPV} / \mathrm{PCM})$ in daytime (Fig. 13). Furthermore, it decreases the risk of overuse PCM latent heat capacity in a previous period and provide better thermal performance of the PCM. In the night-time, thermal emission from the PCM can increase air temperature inside the cavity $\Delta T_{\mathrm{a} \text {,cav }}=1 \mathrm{~K}$ (Fig. 14), which is less than in non-ventilated regime. Accumulated latent thermal energy in the PCM is cooled down by air flow movement. 


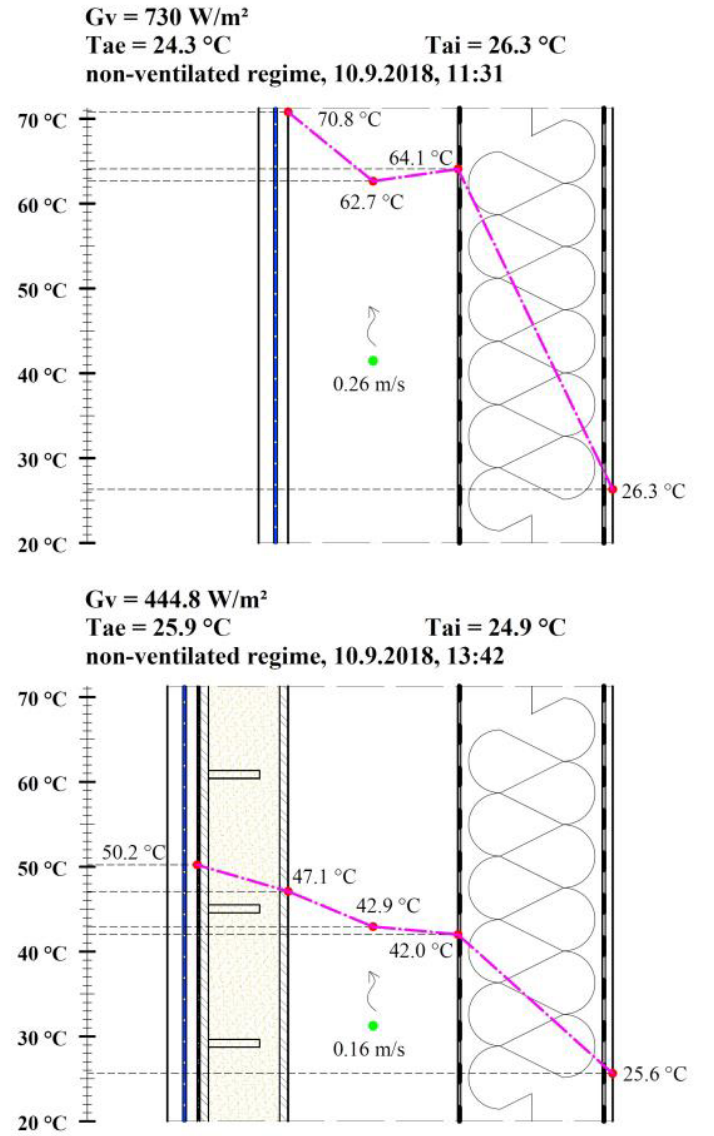

Fig. 11. Peak temperatures and average values of $v_{a, c a v}$ through the non-ventilated façade fragments in the daytime

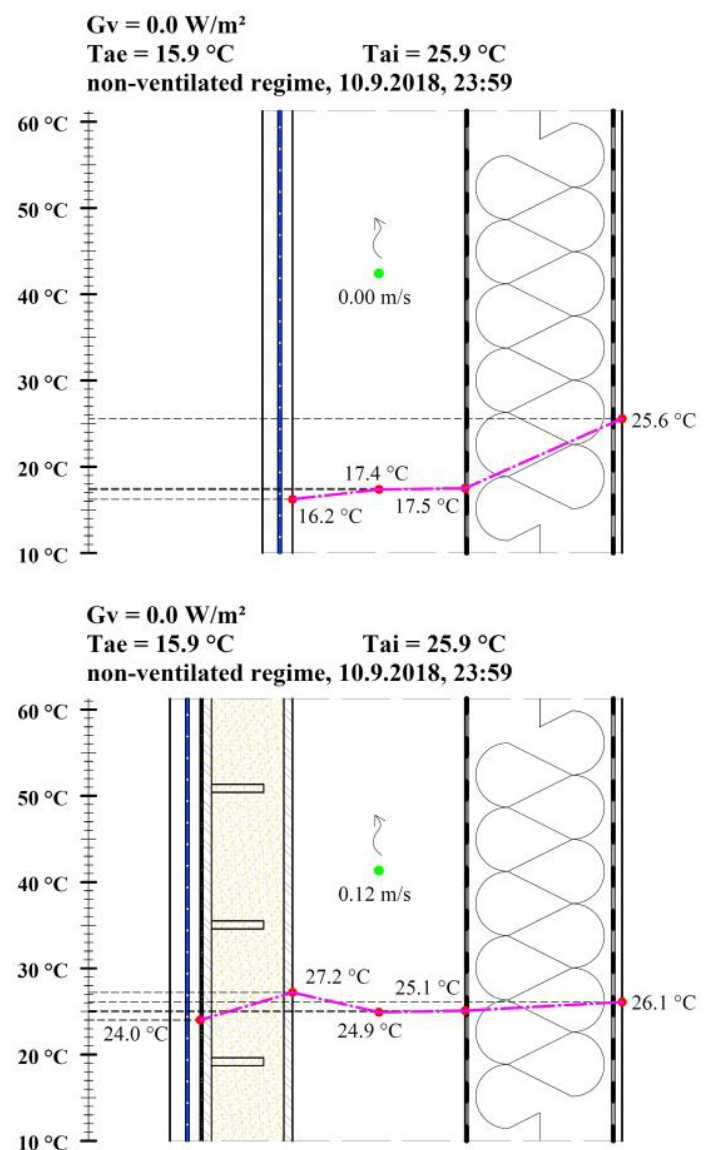

Fig. 12. Peak temperatures and average values of $v_{a}$,cav through the non-ventilated façade fragments in the night-time

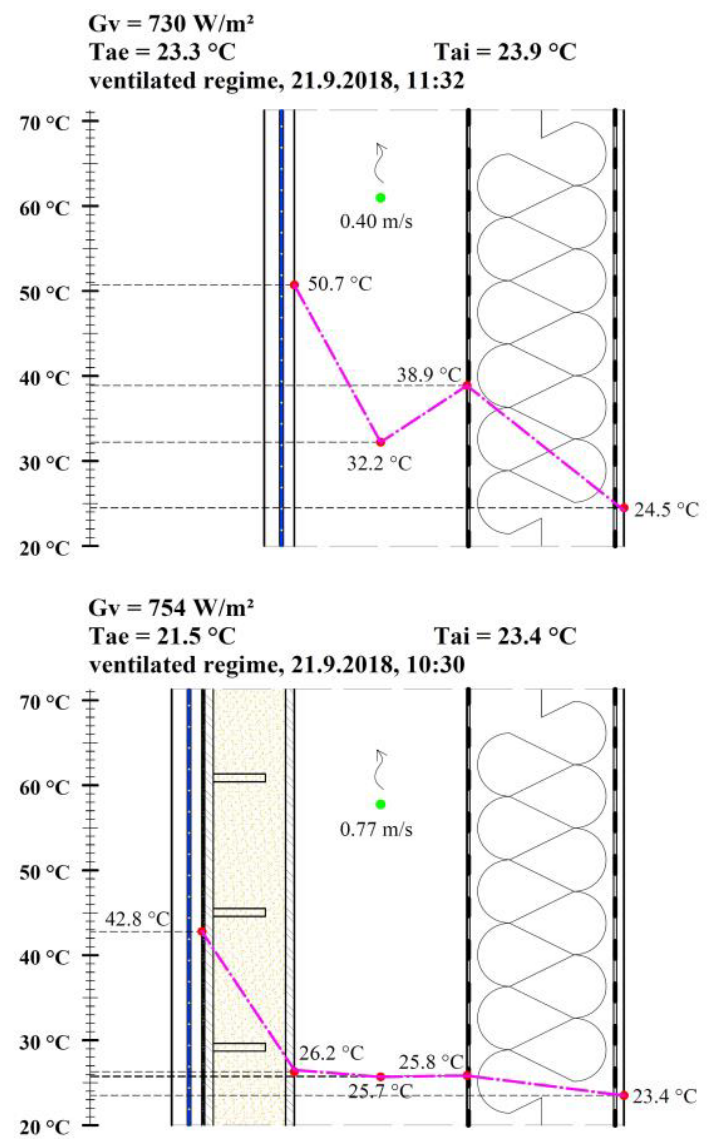

Fig. 13. Peak temperatures and average values of $v_{\mathrm{a}, \mathrm{cav}}$ through the ventilated façade fragments in the daytime

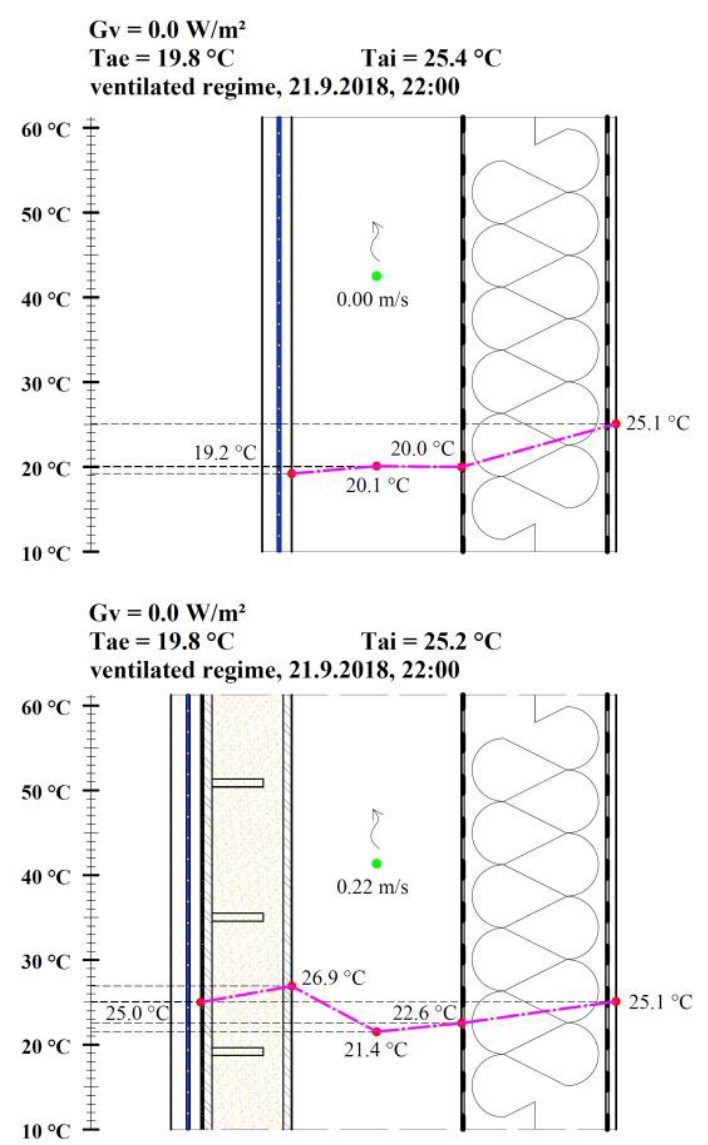

Fig. 14. Peak temperatures and average values of $v_{a, c a v}$ through the ventilated façade fragments in the night-time 


\section{Conclusion}

The aim of the study was to identify an effect of latent thermal energy storage based on the PCM in daytime/night-time of sunny days on the natural ventilation rate of façade air cavity integrated in a BiPV double-skin facade. The dynamic outdoor tests show that on a full-scale experimental mode, a significant difference is measured with the PCM affecting both the enclosed and opened zone of the air facade cavity at the same ventilation regime of a BiPV façade. The effect of thermal inertia plays a key role in the façade cavity and influences differentially its thermal performance in daytime and night-time of a day. Melting and solidification process of PCM according to the outside climate conditions (mainly incident solar radiation) determinates effects of convective and radiant heat transfers in the façade cavity. In non-ventilated regime, the façade cavity of BiPV test sample was significantly overheated in comparison with BiPV/PCM.

The air flow movements in the façade cavity are mainly conditioned by phase change processes of the PCM. Solidification process of the PCM can increase air flow movement and temperatures in the cavity due to emittance of heat energy during the night-time $\left(\Delta v_{\mathrm{ac}}=\right.$ $0.2 \mathrm{~m} / \mathrm{s}$ ). The time of melting process of PCM is higher in case of non-ventilated regime due to full utilization of its latent heat capacity in daytime. However, there are some distinctions in the morning and afternoon parts of a day, where values of $\Delta T_{\mathrm{a} \text {,cav }}$ are higher in the morning ( 5 $-15 \mathrm{~K})$ due to melted state of the PCM in the afternoon. In non-ventilated case, the PCM can decrease the peak value $T_{\mathrm{a} \text {,cav }}$ by $26 \mathrm{~K}$ at midday $(30 \mathrm{~K}$ at the peak level up to $I_{\mathrm{gv}}=780 \mathrm{~W} / \mathrm{m}^{2}$ ) and subsequently during the nighttime increase the temperature by $4 \mathrm{~K}$. On the other hand, in the ventilated case $\Delta T_{\mathrm{a} \text {,cav }}=6 \mathrm{~K}$ at midday and during the night-time of day is increased by $1 \mathrm{~K}$. Surface temperatures inside the façade cavity were significantly influenced by application of PCM, decreased by $20 \mathrm{~K}$ in the daytime (non-ventilated). In this relation and based on previous authors' studies $[15,16]$, the change in surface emissivity in the façade cavity should be carefully considered. This may affect the natural ventilation aspect of a narrow air cavity and the overall heat transfer phenomena as well.

The air temperature differences in the façade cavity are considerable for additional campaign of advanced building energy performance. Accordingly, the solar energy accumulated in the PCM can be additionally used by air circulating in the façade cavity as auxiliary source for decentralised façade ventilation units. The next step of present research will be focused, in accordance to the mentioned hybrid system based on an application of active systems for sensible exploitation of solar heat energy.

This research was supported by the Slovak Research and Development Agency, Project No. APVV-16-0126 and No. APVV-15-0681, projects VEGA $1 / 0050 / 18$ and VEGA $1 / 0680 / 20$ supported by Scientific Grant Agency of the Ministry of Education, Science, Research and Sport of the Slovak Republic, project GA 20-00630S "Climate responsive components integrated in energy and environmentally efficient building envelope" supported by Czech Science Foundation in Czechia.

\section{References}

1. M.J. Huang, P.C. Eames, B. Norton, Solar Energy 80, 1121-1130 (2006)

2. M.J. Huang, Solar Energy Materials \& Solar Cells 95, 957-963 (2011)

3. G. Diarce, A. Urresti, A. Garcia-Romero, A. Delgado, A. Erkoreka, C. Escudero, A. CamposCelador, Applied Energy 103, 530-537 (2013)

4. G. Diarce, A. Campos-Celador, K. Martin, A. Urresti, A. Garcia-Romero, J.M. Sala, Applied Energy 126, 307-317 (2014)

5. A. de Gracia, L. Navarro, A. Castell, A. Ruiz-Pardo, S. Alvárez, Energy and Buildngs 58, 324-332 (2013)

6. Chr. Lamnatoum, G. Notton, D. Chemisana, C. Cristofari, Science of the Total Environment 699, 134269, (2020)

7. T. Ma, Z. Li, J. Zhao, Renewable and Sustainable Energy Reviews 116, 109406, (2019)

8. X. Yang, L. Sun, Y. Yuan, X. Zhao, X. Cao, Renewable Energy 119, 152-159, (2018)

9. A.H.A. Al-Waeli, H.A. Kazem, M.T. Chaichan, K. Sopian, Thermal Science and Engineering Progress 11, 213-230 (2019)

10. Y. Xiang, Experimental and computational investigation of building integrated $P V$ thermal air system combined with thermal storage (PhD thesis, University of Nottingham, 2017)

11. H. Elarga, F. Goia, A. Zarrella, A. Dal Monte, E. Benini, Solar Energy 136, 112-124 (2016)

12. K. Kant, R. Pitchumani, A. Shukla, A. Sharma, Energy Conversion and Management 196, 149-164 (2019)

13. J. Curpek, M. Cekon, J. Hraska, IOP Conference Series: Earth and Environmental Science 290 (1), 012072 (2019)

14. J. Čurpek, M. Čekon, Renewable Energy 152, 368384 (2020)

15. M. Čekon, J. Čurpek, R. Slávik, O. Šikula, Science and Technology for the Built Environment 26 (4), 511-523 (2020)

16. M. Čekon, J. Čurpek, R. Slávik, IOP Conference Series: Materials Science and Engineering 609 (3), 032054 (2019) 